Journal of Zhejiang University-SCIENCE B (Biomedicine \& Biotechnology)

ISSN 1673-1581 (Print); ISSN 1862-1783 (Online)

www.jzus.zju.edu.cn; www.springerlink.com

E-mail: jzus@zju.edu.cn

\title{
Review:
}

\section{Possible aerosol transmission of COVID-19 and special precautions in dentistry ${ }^{*}$}

\author{
Zi-yu GE, Lu-ming YANG, Jia-jia XIA, Xiao-hui FU, Yan-zhen ZHANG ${ }^{\dagger *}$ \\ Department of General Dentistry, the Second Affiliated Hospital, School of Medicine, Zhejiang University, Hangzhou 310009, China \\ †E-mail: 2191004@zju.edu.cn
}

Received Feb. 20, 2020; Revision accepted Feb. 26, 2020; Crosschecked Mar. 3, 2020; Published online Mar. 16, 2020

\begin{abstract}
Since its emergence in December 2019, corona virus disease 2019 (COVID-19) has impacted several countries, affecting more than 90 thousand patients and making it a global public threat. The routes of transmission are direct contact, and droplet and possible aerosol transmissions. Due to the unique nature of dentistry, most dental procedures generate significant amounts of droplets and aerosols, posing potential risks of infection transmission. Understanding the significance of aerosol transmission and its implications in dentistry can facilitate the identification and correction of negligence in daily dental practice. In addition to the standard precautions, some special precautions that should be implemented during an outbreak have been raised in this review.
\end{abstract}

Key words: Corona virus disease 2019 (COVID-19); Aerosol; Infection control https://doi.org/10.1631/jzus.B2010010

CLC number: R780.1; R511

\section{Introduction}

By the end of 2019, a pneumonia outbreak with unknown etiology occurred in Wuhan, China. Most of the cases were linked to a local seafood market selling live animals, suggesting that the pathogens were transmitted from animals to humans, soon escalating to human-to-human transmission. The pathogen was identified and named as 2019 novel coronavirus (2019$\mathrm{nCoV}$ ), and the disease was named corona virus disease 2019 (COVID-19), which stands for coronavirus disease 2019.

Based on the World Health Organization (WHO) report, as of Mar. 6, 2020, there are 98192 confirmed cases of COVID-19 and 3380 deaths, of which 80711 were reported in the Chinese Mainland and 17481 in

\footnotetext{
¿ Corresponding author

* Project supported by the Science Foundation of Zhejiang Province (No. LY20H140001), China

(D) ORCID: Yan-zhen ZHANG, https://orcid.org/0000-0001-7890-6281

(c) Zhejiang University and Springer-Verlag GmbH Germany, part of Springer Nature 2020
}

other 89 countries and regions, including the United Kingdom, the United States, Australia, etc. (WHO, $2020 \mathrm{~b}$ ), resulting in a mortality rate of $2 \%$ ( $\mathrm{Ng}$ et al., 2020) and reproduction number of 1.4-5.5 (Chen, 2020). As the number of confirmed cases continues to rise, global health, economic development, and even social stability are falling under immense pressure. On Jan. 31,2020 , the WHO declared the COVID-19 crisis as a "Public Health Emergency of International Concern."

As stated in the 6th Edition of COVID-19 Treatment Regimen (Trial Implementation) published by the National Health Commission of the People's Republic of China (2020), the possible routes of 2019$\mathrm{nCoV}$ transmission are mainly direct contact and droplet transmission. Aerosol transmission is also a possible route of transmission when there is an exposure to high concentrations of aerosols in a relatively closed environment. Routine dental procedures generate aerosols, which pose potential risks to the dental care personnel and patients. Although there are no reported cases of coronavirus transmission in a dental setting, given the high transmissibility of the 
disease, dental teams should be alert and maintain a healthy environment for both the patients and themselves. Therefore, understanding aerosol transmission and its implications in dentistry is essential. In addition to standard precautions, some special precautions should also be implemented during this special period.

\section{Aerosol transmission and its implication in dentistry}

\subsection{Droplets and aerosols and their significance in the transmission of diseases}

When a person coughs, sneezes, laughs, or talks, large ( $>5 \mu \mathrm{m}$ diameter) and small $(\leq 5 \mu \mathrm{m}$ diameter) droplets or aerosols are generated. Due to gravity, larger droplets fall to the ground quickly; therefore, droplet transmission requires close physical proximity between an infected individual and a susceptible individual. On the other hand, small droplets or small particle residues of evaporated droplets have a low settling velocity, so they may remain in the air for a longer time and travel further before they can enter the respiratory tract or contaminate surfaces (WHO, 2014) (Fig. 1). Results from some studies have shown that aerosols from highly virulent pathogens like severe acute respiratory syndrome-coronavirus (SARS$\mathrm{CoV}$ ) can travel more than six feet (Kutter et al., 2018).
Contaminated surfaces have been found to be a route of transmission of several nosocomial pathogens (Otter et al., 2013). Although human coronaviruses including SARS-CoV and Middle East respiratory syndrome-coronavirus (MERS-CoV) have limited capacity to survive on a dry surface, several studies have reported that they can persist on a surface for a few days, particularly when suspended in human secretion, and undergo onward transmission (Kramer et al., 2006; Otter et al., 2013). Hand contact with contaminated surfaces may lead to pathogen acquisition and transfer to the eyes, nose, or mouth, resulting in a new case of infection (Otter et al., 2013).

\subsection{Droplets and aerosols in dental setting}

When performing dental procedures with a highspeed handpiece, friction between the tooth and the rapidly rotating bur would create excessive heat. Without a coolant, the heat could cause damage to hard dental tissue and lead to pathological changes to the dental pulp. Therefore, to prevent heat gain, it is a universal consensus to use a water coolant when performing dental procedures, including tooth preparation, oral prophylaxis, and oral surgery (Farah, 2019), as shown in Fig. 2.

The water coolant, however, could generate aerosols. When combined with bodily fluids in the oral cavity, such as blood and saliva, bioaerosols are created.

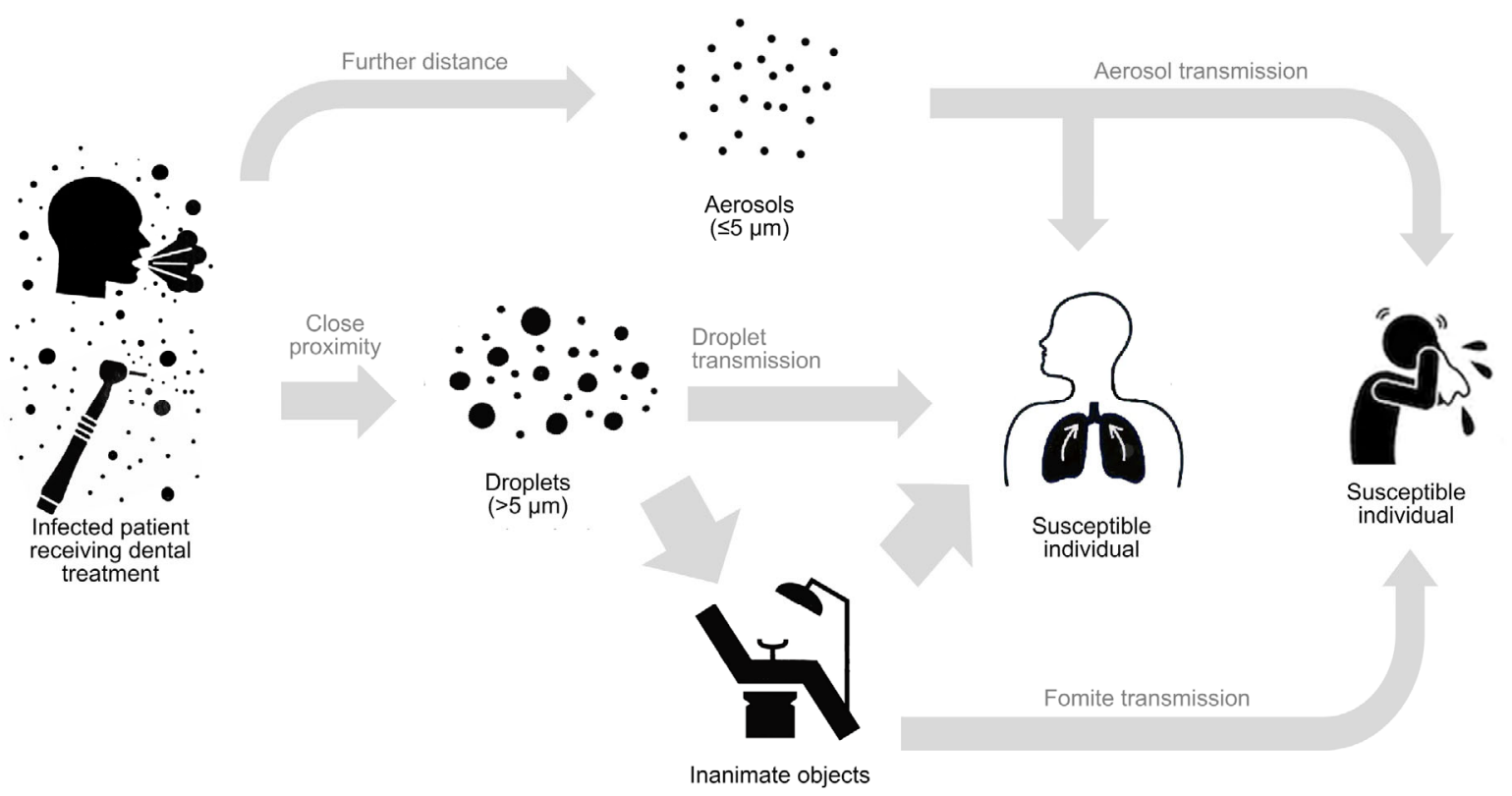

Fig. 1 Different routes of transmission in dental setting: aerosol, droplet, and fomite 

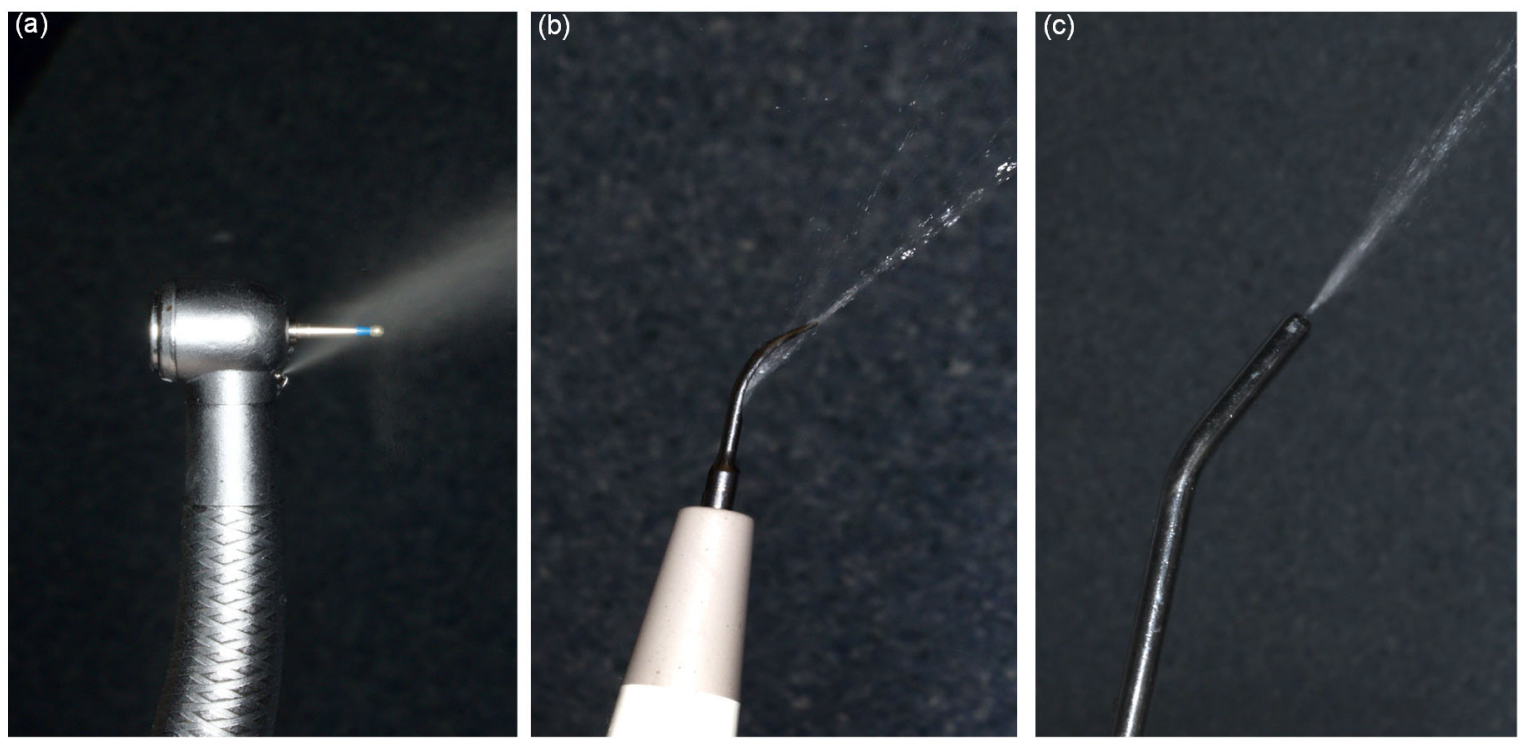

Fig. 2 Aerosols generated by dental high-speed handpiece (a), ultrasonic scaler (b), and air-water syringe (c)

These bioaerosols are commonly contaminated with bacteria, fungi, and viruses, and have the potential to float in the air for a considerable amount of time and be inhaled by the dentists or other patients (Grenier, 1995; Jones and Brosseau, 2015).

A review conducted by Zemouri et al. (2017) showed that 38 types of microorganisms could be found in the air of the dental clinic, including Legionella pneumophila, the causative agent of severe pneumonia. There have been reports of patients acquiring pneumonia after being treated at a dental clinic (Ricci et al., 2012). Another group in the UK reported an outbreak of tuberculosis among dental patients who acquired the infection at their local dentist (Smith et al., 1982). In terms of coronavirus, a study conducted by Wang et al. (2004) examined the oral cavity of SARS patients and found large amount of SARS-CoV RNA in their saliva $\left(\left(7.08 \times 10^{3}\right)\right.$ to $\left(6.38 \times 10^{8}\right)$ copies $\left./ \mathrm{mL}\right)$, suggesting the possibility of coronavirus transmission through oral droplets. Past evidence showed that the majority of SARS-CoV and MERS-CoV cases were associated with nosocomial transmission in hospitals, resulting, partly, from the use of aerosol-generating procedures performed on patients with respiratory disease (Chowell et al., 2015). Based on the current epidemiological data, 2019-nCoV has higher transmissibility than SARS-CoV and MERS-CoV (Chen, 2020). Therefore, modification of standard precaution and infection control regimen targeted toward 2019$\mathrm{nCoV}$ is essential during this outbreak.

\section{Special precautions in dental setting}

The outbreak of COVID-19 has clearly placed health professionals at risk. Infection with $2019-\mathrm{nCoV}$ has been detected in health care workers (HCWs), and the number of such cases is gradually increasing ( $\mathrm{Li}$ et al., 2020). Based on the information extracted from China's Infectious Disease Information System, a total of $1716 \mathrm{HCWs}$ have been infected with 2019-nCoV, with five reported deaths (The Novel Coronavirus Pneumonia Emergency Response Epidemiology Team, 2020). Ensuring health and personal safety for HCWs is essential, as an infected HCW could also posit a source of cross-transmission.

Fortunately, there are no reported cases of COVID-19 transmission in the dental setting. Nevertheless, with the given evidence that the incubation period lasts up to $14 \mathrm{~d}$ (Jin et al., 2020), it is not always possible to identify asymptotic carriers early or without testing. Furthermore, there has been a report of infection transmission from asymptomatic contact, implying that COVID-19 is contagious during the incubation period (Rothe et al., 2020). Thus, aside from following the principle of universal precaution, special precautionary measures targeted toward aerosol transmission should also be taken to prevent and control the spread of this highly contagious disease. Interestingly, a group of scientists from China have reported that the cell receptor for 2019-nCoV infection, angiotensin-converting enzyme II (ACE2), is highly 
expressed on the mucosa of the oral cavity. Notably, this receptor is present in large amounts in the epithelial cells of the tongue (Xu et al., 2020). These findings indicate that the oral cavity is a potentially high-risk transmitter of 2019-nCoV infection and can be used in future prevention strategies in the dental/ clinical setting.

During routine dental practice, guidelines of the Clinical Technique for Oral Medicine (2017 Edition) and Clinical Treatment Guidance for Oral Medicine (2016 Edition) produced by Chinese Stomatological Association, and Summary of Infection Prevention Practices in Dental Settings produced by the Center for Disease Control and Prevention in the United States (CDC) are usually followed as "standard precautions" of infection control (Chinese Stomatological Association, 2017, 2016; Centers for Disease Control and Prevention, 2016). In light of the continuously updated epidemiological data on COVID-19, here, we propose several special precautions in addition to the "standard precautions" that can be applied in dental care settings during this outbreak. Our recommendations are based on the COVID-19 interim guidance set forth by the WHO (2020c) and our own current clinical practice in China.

\subsection{Special precautions in dental emergency during COVID-19 outbreak}

Due to the special characteristics of dentistry and the high transmissibility of COVID-19, dental hospitals and clinics around China are temporarily closed to prevent the potential risk of transmission. However, there are dental emergencies that require immediate treatment and control, such as trauma, fascial space infection, and carcinoma. Therefore, special precautions should be followed when treating dental emergencies.

1. Patient screening: As is the routine, dentists should take a thorough medical history from each patient and confirm the health status at each recall visit. During this outbreak, targeted screening questions for COVID-19 must be asked. These questions should include personal, travel, and epidemiological history. Temperature and lower respiratory tract symptoms should be closely monitored. Note that symptoms of fever and fatigue could be caused by acute dental infection; therefore, the etiology should be confirmed.

2. For patients whose infections are dental in origin, emergency treatments could be performed following standard dental emergency regimen.
3. For suspected/confirmed cases of COVID-19 that are medically stable, laboratory tests and multidisciplinary team consultations should be performed. To ensure the safety of patients and HCWs, the patient should be rescheduled after the outbreak if required.

4. For suspected/confirmed cases of COVID-19 requiring urgent dental treatment, highest level of personal protection should be implemented. To facilitate natural ventilation, WHO (2020a) recommends the use of a negative pressure room with a minimum of 12 air changes per hour or at least $160 \mathrm{~L} / \mathrm{s}$ per patient. Mechanical ventilation should commence before treating the next patient.

\subsection{Special precautions in routine practice}

\subsubsection{Waiting area}

Post a cough etiquette instruction at the entrance of the waiting room. Ensure that all patients cover their nose and mouth with a tissue or their elbow when coughing or sneezing; instruct them to dispose used tissues into a waste bin immediately after use and ensure hand hygiene.

Patients should be placed in an adequately ventilated waiting area. For rooms with natural ventilation, $60 \mathrm{~L} / \mathrm{s}$ per patient is considered adequate ventilation (Atkinson et al., 2009).

Spatial separation of at least $1 \mathrm{~m}$ should be maintained between patients.

Equipment such as blood pressure cuffs and thermometers should be cleaned and disinfected with $70 \%$ ethyl alcohol after each use, as recommended by the WHO (2016).

\subsubsection{Hand hygiene}

There is a growing awareness of the importance of handwashing in the prevention of acute respiratory infections. During the outburst of SARS, several epidemiological studies suggested that handwashing with soap and $70 \%-90 \%$ alcohol-based hand rubs (ABHRs) was effective in curbing SARS transmission (Rabenau et al., 2005; Fung and Cairncross, 2006).

The WHO (2020c) stated that hand hygiene includes either cleansing hands with an ABHR or with soap and water; both methods are equally effective. ABHRs are preferred if the hands are not visibly soiled; if the hands are visibly soiled, water and soap should be used. 
As suggested by WHO (2009), hand hygiene should be performed before touching a patient, before any cleaning or aseptic procedure is performed, after exposure to body fluid, after touching a patient, and after touching a patient's surroundings.

\subsubsection{Personal protective equipment}

During dental practices, the spread of oral microorganisms mostly radiates toward the dentist's face, particularly in the inner part of the eyes and around the nose, which are important areas for infection transmission (Bentley et al., 1994; Nejatidanesh et al., 2013). Personal protective equipment (PPE) can form an effective barrier against most hazards of aerosols generated from the operative site.

1. Protective eyewear and face shields: It is clinically evident that COVID-19 may also be transmitted through contact with the mucous membranes in eyes, as infectious droplets could easily contaminate the human conjunctival epithelium (Lu et al., 2020). To protect the eyes from aerosols and debris created during dental procedure, protective eyewear or face shield should be worn throughout the treatment and disinfected between patients.

2. Face masks: At minimum, a medical mask (surgical or procedure mask) was used if working at a distance of less than $1 \mathrm{~m}$ from the patient. When performing aerosol generating procedures (using high-speed handpiece, air-water syringe, and ultrasonic scaler), a particulate respirator that is at least as protective as a National Institute for Occupational Safety and Health (NIOSH)-certified N95, European Standard Filtering Face Piece 2 (EU FFP2), or equivalent, was used. When performing emergency dental treatment with suspected COVID-19 cases, a higher level of respiratory protection should be considered, such as EU FFP3 respirators conforming to European Standard 149 (EN149).

\subsubsection{Preprocedural mouth rinse}

Preprocedural mouth rinse is one of the most effective methods of reducing the proportion of microorganisms in oral aerosols (Samaranayake and Peiris, 2004; Feres et al., 2010). A meta-analysis showed that the use of preprocedural mouth rinse, including chlorhexidine (CHX), essential oils, and cetylpyridinium chloride (CPC), resulted in a mean reduction of $68.4 \%$ colony-forming units in dental aerosol (Marui et al., 2019). Although the effect of preprocedural mouth rinse against coronavirus is still unknown, it has been proven that CHX is effective against several infectious viruses, including herpes simple virus (HSV), human immunodeficiency virus (HIV), and hepatitis $B$ virus (HBV) (Wood and Payne, 1998)

About $0.12 \%$ CHX was used as a preprocedural mouth rinse. For patients who develop mucosal irritation or other side effects such as tongue stain, $0.05 \%$ CPC could be a good alternative (Feres et al., 2010).

\subsubsection{Rubber dam isolation}

During dental procedures that generate aerosols, rubber dam provides barrier protection from the primary source and will virtually eliminate all pathogens emerging from respiratory secretion. If the rubber dam is placed correctly, the only source of contamination would be the tooth that is undergoing treatment (Harrel and Molinari, 2004). Application of rubber dam during cavity preparation showed a significant reduction in the spread of microorganisms by $90 \%$ (Cochran et al., 1989). Rubber dam is applied in all aerosol-generating procedures. One disadvantage of using the rubber dam is that it is not feasible in procedures that require subgingival instrumentation, such as subgingival restoration and subgingival crown margin preparation. We propose several alternations in Table 1.

\subsubsection{Removal/filter of contaminated air}

There are several methods to remove/filter contaminated air in treatment areas; the two most commonly used devices include the inexpensive highvolume evacuator (HVE) and the expensive highefficiency particulate arrestor (HEPA) filters.

HVE filter: It is a suction device that helps remove air at a rate of up to $2.83 \mathrm{~m}^{3}$ per minute. It is the easiest way to remove dental aerosols as they are generated and could effectively reduce contamination caused by the operating site by $90 \%$ (Narayana et al., 2016). However, the device should be held at a proper distance (approximately $6-15 \mathrm{~mm}$ ) from the active ultrasonic tip. One limitation of the HVE is that without a dental assistant, clinicians might face difficulty in operating it using one hand. There are modified HVEs in the market that address this problem.

HEPA filter: It is an air filtration device that can remove $99.97 \%$ of the particles measuring $0.3 \mu \mathrm{m}$ in diameter. One disadvantage is that the filter may become a source of microbes if the retained microorganisms proliferate and enter back into the filtered air 
Table 1 Strategies to reduce droplet generation in different dental disciplines

\begin{tabular}{lc}
\hline Dental discipline & Special precaution \\
\hline Endodontics & Rubber dam must be applied during endodontic treatment \\
& Root canal treatment usually requires a number of endodontic instruments and devices, \\
& therefore minimizing unnecessary hand contact with surfaces and equipment in the \\
dental office to reduce possibility of fomite transmission \\
Avoid using rotary instruments during cavity preparation. In selective cases, consider using \\
chemochemical caries removal or atraumatic restorative techniques \\
pediatric dentistry \\
If rotary instrumentation must be performed, rubber dam isolation should be applied \\
Heriodontics \\
Hand and ultrasonic instrumentation are equally effective in removing plaque and calculus \\
deposits; if required, manual scaling and polishing are recommended (Krishna and \\
de Stefano, 2016) \\
Salivary suction must be performed with care to avoid gagging \\
Select and adjust trays to the right size for impression taking to avoid cough reflex. For \\
highly sensitive patients, consider applying oral mucosa anesthesia to the throat before \\
impression taking \\
During fixed partial denture or single-crown preparation, treatment alternation may be \\
considered to incorporate rubber dam application. For example, design supra-gingival \\
margin for posterior bridge or use a split-dam technique (Li et al., 2004) \\
During removable partial denture or complete denture try-in, avoid touching other objects \\
in the dental office after contacting patients' saliva \\
Upon removal from patient's mouth, dental prosthesis, impressions, and other prosthodon- \\
tics materials (e.g., bite registration) should be thoroughly disinfected by a disinfectant \\
having at least intermediate level activity \\
When performing simple extraction, treat the patient in a supine position to avoid working \\
in the breath way of a patient
\end{tabular}

(Chuaybamroong et al., 2010). In addition, soiled HEPA filters are difficult to clean and expensive to replace (Day et al., 2018).

\subsubsection{Environmental surface disinfection}

During aerosol generating procedures, droplets containing infective pathogens could be deposited on the surrounding surfaces. An analysis of 22 studies revealed that human coronaviruses, such as SARS and MERS, can persist on inanimate surfaces for up to $9 \mathrm{~d}$. However, they can be efficiently inactivated by surface disinfects within one minute. These surface disinfectants contain $62 \%-71 \%$ ethanol, $0.5 \%$ hydrogen peroxide, and $0.1 \%(1 \mathrm{~g} / \mathrm{L})$ sodium hypochlorite (Kampf et al., 2020). Surfaces are disinfected after each patient visits, especially surfaces in close proximity to the operating areas.

3.2.8 Other methods to reduce droplet generation in different dental disciplines

Based on the features of different dental disciplines (Table 1), we summarize some strategies that could be implemented in some dental specialties to reduce droplet generation.

\section{Conclusions}

Dentists, by nature, are at high risk of exposure to infectious diseases. The emergence of COVID-19 has brought new challenges and responsibilities to dental professionals. A better understanding of aerosol transmission and its implication in dentistry can help us identify and rectify negligence in daily dental practice. In addition to the standard precautions, implementation of special precautions could prevent disease transmission from asymptomatic carriers. These special precautions would not only help control the spread of COVID-19 but also serve as a guide for managing other respiratory diseases.

\section{Contributors}

Zi-yu GE and Lu-ming YANG analyzed the literatures and prepared the first draft of the manuscript. Jia-jia XIA, Xiao-hui FU, and Yan-zhen ZHANG revised, edited, and checked the final version. All authors have read and approved the final manuscript.

\section{Compliance with ethics guidelines}

Zi-yu GE, Lu-ming YANG, Jia-jia XIA, Xiao-hui FU, and Yan-zhen ZHANG declare that they have no conflict of interests. 
This article does not contain any studies with human or animal subjects performed by any of the authors.

\section{References}

Atkinson J, Chartier Y, Pessoa-Silva CL, et al., 2009. Natural Ventilation for Infection Control in Health-Care Settings. World Health Organization, Geneva, Switzerland.

Bentley CD, Burkhart NW, Crawford JJ, 1994. Evaluating spatter and aerosol contamination during dental procedures. $J$ Am Dent Assoc, 125(5):579-584.

https://doi.org/10.14219/jada.archive.1994.0093

Centers for Disease Control and Prevention, 2016. Summary of Infection Prevention Practices in Dental Settings: Basic Expectations for Safe Care. Centers for Disease Control and Prevention, US Department of Health and Human Services, Atlanta, USA, p.8-16.

Chen JL, 2020. Pathogenicity and transmissibility of 2019-nCoVa quick overview and comparison with other emerging viruses. Microbes Infect, in press. https://doi.org/10.1016/j.micinf.2020.01.004

Chinese Stomatological Association, 2016. Clinical Treatment Guidance for Oral Medicine, 2016 Ed. People's Medical Publishing House, Beijing, China (in Chinese).

Chinese Stomatological Association, 2017. Guidelines of the Clinical Technique for Oral Medicine, 2017 Ed. People's Medical Publishing House, Beijing, China (in Chinese).

Chowell G, Abdirizak F, Lee S, et al., 2015. Transmission characteristics of MERS and SARS in the healthcare setting: a comparative study. BMC Med, 13:210. https://doi.org/10.1186/s12916-015-0450-0

Chuaybamroong P, Chotigawin R, Supothina S, et al., 2010. Efficacy of photocatalytic HEPA filter on microorganism removal. Indoor Air, 20(3):246-254. https://doi.org/10.1111/j.1600-0668.2010.00651.x

Cochran MA, Miller CH, Sheldrake MA, 1989. The efficacy of the rubber dam as a barrier to the spread of microorganisms during dental treatment. $J$ Am Dent Assoc, 119(1): 141-144. https://doi.org/10.14219/jada.archive.1989.0131

Day DB, Xiang J, Mo J, et al., 2018. Combined use of an electrostatic precipitator and a high-efficiency particulate air filter in building ventilation systems: effects on cardiorespiratory health indicators in healthy adults. Indoor Air, 28(3):360-372. https://doi.org/10.1111/ina.12447

Farah RI, 2019. Effect of cooling water temperature on the temperature changes in pulp chamber and at handpiece head during high-speed tooth preparation. Restor Dent Endod, 44(1):e3. https://doi.org/10.5395/rde.2019.44.e3

Feres M, Figueiredo LC, Faveri M, et al., 2010. The effectiveness of a preprocedural mouthrinse containing cetylpyridinium chloride in reducing bacteria in the dental office. $J$ Am Dent Assoc, 141(4):415-422. https://doi.org/10.14219/jada.archive.2010.0193

Fung ICH, Cairncross S, 2006. Effectiveness of handwashing in preventing SARS: a review. Trop Med Int Health, 11(11): 1749-1758.

https://doi.org/10.1111/j.1365-3156.2006.01734.x

Grenier D, 1995. Quantitative analysis of bacterial aerosols in two different dental clinic environments. Appl Environ Microbiol, 61(8):3165-3168.

https://doi.org/10.1128/AEM.61.8.3165-3168.1995

Harrel SK, Molinari J, 2004. Aerosols and splatter in dentistry: a brief review of the literature and infection control implications. J Am Dent Assoc, 135(4):429-437. https://doi.org/10.14219/jada.archive.2004.0207

Jin YH, Cai L, Cheng ZS, et al., 2020. A rapid advice guideline for the diagnosis and treatment of 2019 novel coronavirus (2019-nCoV) infected pneumonia (standard version). Military Med Res, 7:4. https://doi.org/10.1186/s40779-020-0233-6

Jones RM, Brosseau LM, 2015. Aerosol transmission of infectious disease. J Occup Environ Med, 57(5):501-508. https://doi.org/10.1097/JOM.0000000000000448

Kampf G, Todt D, Pfaender S, et al., 2020. Persistence of coronaviruses on inanimate surfaces and their inactivation with biocidal agents. $J$ Hosp Infect, online ahead of print. https://doi.org/10.1016/j.jhin.2020.01.022

Kramer A, Schwebke I, Kampf G, 2006. How long do nosocomial pathogens persist on inanimate surfaces? A systematic review. BMC Infect Dis, 6:130. https://doi.org/10.1186/1471-2334-6-130

Krishna R, de Stefano JA, 2016. Ultrasonic vs. hand instrumentation in periodontal therapy: clinical outcomes. Periodontology, 71(1):113-127. https://doi.org/10.1111/prd.12119

Kutter JS, Spronken MI, Fraaij PL, et al., 2018. Transmission routes of respiratory viruses among humans. Curr Opin Virol, 28:142-151. https://doi.org/10.1016/j.coviro.2018.01.001

Li Q, Guan XH, Wu P, et al., 2020. Early transmission dynamics in Wuhan, China, of novel coronavirus-infected pneumonia. NEngl J Med, online. https://doi.org/10.1056/NEJMoa2001316

Li RWK, Leung KWC, Sun FCS, et al., 2004. Severe acute respiratory syndrome (SARS) and the GDP. Part II: implications for GDPs. Br Dent J, 197(3):130-134. https://doi.org/10.1038/sj.bdj.4811522

Lu CW, Liu XF, Jia ZF, 2020. 2019-nCoV transmission through the ocular surface must not be ignored. Lancet, 395(10224):PE39. https://doi.org/10.1016/S0140-6736(20)30313-5

Marui VC, Souto MLS, Rovai ES, et al., 2019. Efficacy of preprocedural mouthrinses in the reduction of microorganisms in aerosol: a systematic review. J Am Dent Assoc, 150(12):1015-1026.e1. https://doi.org/10.1016/j.adaj.2019.06.024

Narayana TV, Mohanty L, Sreenath G, et al., 2016. Role of preprocedural rinse and high volume evacuator in reducing bacterial contamination in bioaerosols. J Oral Maxillofac 
Pathol, 20(1):59-65. https://doi.org/10.4103/0973-029X.180931

National Health Commission of the People's Republic of China, 2020. 6th Edition of COVID-19 Treatment Regimen (Trial Implementation) (in Chinese). http://www. nhc.gov.cn/yzygj/s7653p/202002/8334a8326dd94d329df 351d7da8aefc2.shtml [Accessed on Mar. 7, 2020].

Nejatidanesh F, Khosravi Z, Goroohi H, et al., 2013. Risk of contamination of different areas of dentist's face during dental practices. Int J Prev Med, 4(5):611-615.

$\mathrm{Ng}$ MY, Lee EY, Yang J, et al., 2020. Imaging profile of the COVID-19 infection: radiologic findings and literature review. Radiol Cardiothorac Imaging, 2(1):e200034. https://doi.org/10.1148/ryct.2020200034

The Novel Coronavirus Pneumonia Emergency Response Epidemiology Team, 2020. The epidemiological characteristics of an outbreak of 2019 novel coronavirus diseases (COVID-19) in China. Chin J Epidemiol, 41(2):145 (in Chinese).

https://doi.org/10.3760/cma.j.issn.0254-6450.2020.02.003

Otter JA, Yezli S, Salkeld JAG, et al., 2013. Evidence that contaminated surfaces contribute to the transmission of hospital pathogens and an overview of strategies to address contaminated surfaces in hospital settings. Am J Infect Control, 41(5):S6-S11. https://doi.org/10.1016/j.ajic.2012.12.004

Rabenau HF, Kampf G, Cinatl J, et al., 2005. Efficacy of various disinfectants against SARS coronavirus. J Hosp Infect, 61(2):107-111. https://doi.org/10.1016/j.jhin.2004.12.023

Ricci ML, Fontana S, Pinci F, et al., 2012. Pneumonia associated with a dental unit waterline. Lancet, 379(9816):684. https://doi.org/10.1016/S0140-6736(12)60074-9

Rothe C, Schunk M, Sothmann P, et al., 2020. Transmission of 2019-nCoV infection from an asymptomatic contact in Germany. N Engl J Med, 382:970-971. https://doi.org/10.1056/NEJMc2001468

Samaranayake LP, Peiris M, 2004. Severe acute respiratory syndrome and dentistry: a retrospective view. $\mathrm{J} \mathrm{Am}$ Dental Assoc, 135(9):1292-1302. https://doi.org/10.14219/jada.archive.2004.0405

Smith WHR, Mason KD, Davies D, et al., 1982. Intraoral and pulmonary tuberculosis following dental treatment. Lancet, 319(8276):842-844. https://doi.org/10.1016/s0140-6736(82)91886-4

Wang WK, Chen SY, Liu IJ, et al., 2004. Detection of SARSassociated coronavirus in throat wash and saliva in early diagnosis. Emerg Infect Dis, 10(7):1213-1219. https://doi.org/10.3201/eid1007.031113

WHO, 2009. WHO Guidelines on Hand Hygiene in Health Care: First Global Patient Safety Challenge - Clean Care is Safer Care. World Health Organization, Geneva, Switzerland. WHO, 2014. Infection Prevention and Control of Epidemic- and Pandemic-Prone Acute Respiratory Infections in Health Care. World Health Organization, Geneva, Switzerland.

WHO, 2016. Decontamination and Reprocessing of Medical Devices for Health-Care Facilities. World Health Organization, Geneva, Switzerland.

WHO, 2020a. Clinical Management of Severe Acute Respiratory Infection when Novel Coronavirus (2019-nCoV) Infection is Suspected: Interim Guidance. World Health Organization, Geneva, Switzerland.

WHO, 2020b. Coronavirus Disease 2019 (COVID-19): Situation Report, 46. World Health Organization, Geneva, Switzerland.

WHO, 2020c. Infection Prevention and Control During Health Care when Novel Coronavirus (nCoV) Infection is Suspected: Interim Guidance. World Health Organization, Geneva, Switzerland. https://www.who.int/publicationsdetail/infection-prevention-and-control-during-health-carewhen-novel-coronavirus-(ncov)-infection-is-suspected-2 0200125 [Accessed on Jan. 25, 2020].

Wood A, Payne D, 1998. The action of three antiseptics/ disinfectants against enveloped and non-enveloped viruses. J Hosp Infect, 38(1):283-295. https://doi.org/10.1016/s0195-6701(98)90077-9

Xu H, Zhong L, Deng JX, et al., 2020. High expression of ACE2 receptor of 2019-nCoV on the epithelial cells of oral mucosa. Int J Oral Sci, 12(1):1-5. https://doi.org/10.1038/s41368-020-0074-x

Zemouri C, de Soet H, Crielaard W, et al., 2017. A scoping review on bio-aerosols in healthcare and the dental environment. PLoS ONE, 12(5):e0178007. https://doi.org/10.1371/journal.pone.0178007

\section{中文概要}

\section{题 目: 新型冠状病毒可能的气溶胶传播与口腔诊疗防护 的特殊性}

概 要: 自 2019 年 12 月中国武汉出现新型冠状病毒肺炎 (COVID-19) 以来, 多个国家受到影响, 已经 有 9 万多名患者确诊。新型冠状病毒肺炎已经成 为了一个受全世界关注的公共卫生事件。 COVID-19 的主要传播途径有接触传播和飞沫传 播, 以及可能的气溶胶传播。口腔科诊疗的特殊 性使空气中极易产生气溶胶。认识和了解气溶胶 的传播方式和口腔治疗可能产生的影响有利于 发现日常口腔诊疗中存在的纰漏并对其进行改 进。我们还针对疫情期间的口腔急诊及常规口腔 诊疗提出了除标准防护外特殊的防护措施, 以指 导临床工作。

关键词: 新型冠状病毒肺炎; 气溶胶; 感染控制 